\title{
Relationships between particles, cloud condensation nuclei and cloud droplet activation during the third Pallas Cloud Experiment
}

\author{
T. Anttila ${ }^{1}$, D. Brus ${ }^{1}$, A. Jaatinen ${ }^{2}$, A.-P. Hyvärinen ${ }^{1}$, N. Kivekäs ${ }^{1}$, S. Romakkaniemi ${ }^{2}$, M. Komppula ${ }^{3}$, and \\ H. Lihavainen ${ }^{1}$ \\ ${ }^{1}$ Finnish Meteorological Institute, P.O. Box 503, 00101 Helsinki, Finland \\ ${ }^{2}$ University of Eastern Finland, Kuopio Campus, Department of applied physics, P.O. Box 1627, 70211 Kuopio, Finland \\ ${ }^{3}$ Finnish Meteorological Institute, Kuopio Unit, P.O. Box 1627, 70211 Kuopio, Finland
}

Correspondence to: T. Anttila (tatu.anttila@ fmi.fi)

Received: 14 May 2012 - Published in Atmos. Chem. Phys. Discuss.: 4 June 2012

Revised: 30 October 2012 - Accepted: 22 November 2012 - Published: 3 December 2012

\begin{abstract}
Concurrent measurement of aerosols, cloud condensation nuclei $(\mathrm{CCN})$ and cloud droplet activation were carried out as a part of the third Pallas Cloud Experiment (PaCE-3) which took place at a ground based site located on northern Finland during the autumn of 2009. In this study, we investigate relationships between the aerosol properties, $\mathrm{CCN}$ and size resolved cloud droplet activation. During the investigated cloudy periods, the inferred number of cloud droplets (CDNC) varied typically between 50 and $150 \mathrm{~cm}^{-3}$ and displayed a linear correlation both with the number of particles having sizes over $100 \mathrm{~nm}$ and with the CCN concentrations at $0.4 \%$ supersaturation. Furthermore, the diameter corresponding to the $50 \%$ activation fraction, $D_{50}$, was generally in the range of 80 to $120 \mathrm{~nm}$. The measured CCN concentrations were compared with predictions of a numerical model which used the measured size distribution and size resolved hygroscopicity as input. Assuming that the droplet surface tension is equal to that of water, the measured and predicted CCN concentrations were generally within $30 \%$. We also simulated size dependent cloud droplet activation with a previously developed air parcel model. By forcing the model to reproduce the experimental values of CDNC, adiabatic estimates for the updraft velocity and the maximum supersaturation reached in the clouds were derived. Performed sensitivity studies showed further that the observed variability in CDNC was driven mainly by changes in the particle size distribution while the variations in the updraft velocity and hygroscopicity contributed to a lesser extent. The results of the study corroborate conclusions of previous studies according to which the number of cloud droplets formed in
\end{abstract}

clean air masses close to the Arctic is determined mainly by the number of available $\mathrm{CCN}$.

\section{Introduction}

Representation of clouds in large scale models is a major source of uncertainty in climate change predictions (Forster et al., 2007). The uncertainty stems partly from the fact that global climate models have coarse spatial resolution due to the limited computing resources available, and therefore such models cannot resolve the microphysical processes involved in the cloud formation explicitly. Droplets that make up liquid phase clouds in the atmosphere are formed on aerosol particles called as cloud condensation nuclei $(\mathrm{CCN})$ on air containing supersaturated water vapour. The size distribution and chemical composition of aerosols are the key properties that determine the number of $\mathrm{CCN}$ formed at a certain water vapour supersaturation (McFiggans et al., 2006). On the other hand, locally and temporally highly variable meteorological conditions influence the water vapour supersaturation levels reached in ambient clouds (Rogers and Yau, 1989). Several microphysical parameterizations have been developed, implemented and tested in global models (Penner et al., 2007; Ghan et al., 2011) to tackle the problem of describing cloud formation on physical basis in large scale models. Despite these developments, further empirical and process level model studies on the relationships between aerosols, $\mathrm{CCN}$ and cloud microphysics are needed to increase our 
understanding on the climatic effects of aerosols (Ghan and Schwartz, 2007).

Atmospheric in situ studies involving concurrent measurements of aerosols and warm cloud microphysics can be roughly classified into two categories: those involving $\mathrm{CCN}$ measurements at a known water vapour supersaturation $s$, and measurements performed in clouds where cloud droplet number concentrations (CDNC) are measured directly. In the first type of measurements, conditions are more constrained as $s$ can be varied within the operational limits of the $\mathrm{CCN}$ measurement instrument which allows for determining the so called CCN spectrum, i.e. number of $\mathrm{CCN}$ as a function of $s$. Concurrent measurements of the aerosol chemical composition allow further for performing a $\mathrm{CCN}$ closure study where the CCN spectrum is calculated on the basis of the Koehler theory and compared with the measured spectrum (McFiggans et al., 2006). Such closure studies provide a test for our knowledge on the physics behind CCN activity of ambient particles and they also provide insight to the relative importance of the particle size and chemical composition (e.g. Dusek et al., 2006; Hudson et al., 2008; Quinn et al., 2008; Jurányi et al., 2010; Kammermann et al., 2010). On the other hand, as the water vapour supersaturation is kept constant in such studies, the results do not contribute towards understanding the dynamics of cloud formation. Therefore aerosol-CCN closure studies do not provide information on the relative impacts of $\mathrm{CCN}$ spectrum and meteorological conditions in determining CDNC.

Compared to "static" CCN studies, in situ cloud measurements provide direct information on the relationship between aerosols and cloud droplets. These studies may also feature concurrent measurements of $\mathrm{CCN}$ concentrations, the particle chemical composition, the water vapour supersaturation levels and updraft velocities in the observed clouds. Such measurements allow for performing a kinetic closure study where the observed CDNC are compared with those predicted either by a cloud droplet activation parameterization or by a box model that simulates cloud formation taking place under adiabatic conditions (Yum et al., 1998; Snider et al., 2003; Conant et al., 2004; Meskhidze et al., 2005; Fountoukis et al., 2007; Romakkaniemi et al., 2009). Compared to "static" CCN closure studies, kinetic closure studies involve more uncertain variables, but they provide information on the meteorological conditions underlying the cloud formation. Kinetic closure studies can also be complimented with static CCN closure calculations to investigate aerosolCCN and CCN-CDNC relationships (e.g. Yum et al., 1998; Snider et al., 2003; Conant et al., 2004).

While the aerosol-CDNC relationships are typically based on in-cloud measurements performed with an aircraft, several ground-based studies focusing on aerosol-cloud relations have been carried out during the last two decades as well (Anttila et al., 2009 and references therein). These studies have shed light on the importance of the particle size, mixing state and chemical composition to the formation of warm clouds. On the other hand, investigating the impact of meteorology has been more difficult task in ground-based studies (Verheggen et al., 2007) and concurrent CCN measurements have often been lacking.

In this study, we focus on concurrent measurements of aerosols, $\mathrm{CCN}$ and cloud droplet activation that were carried out as a part of the third Pallas Cloud Experiment (PaCE3). The campaign took place at a Pallas Global Atmospheric Watch station located in northern Finland (Hatakka et al., 2003) between September 11th and October 10th of 2009. The current study extends the work carried out during the first two PaCE campaigns (Lihavainen et al., 2008; Anttila et al., 2009; Kivekäs et al., 2009). In the work of Lihavainen et al. (2008), connections between observed aerosol number concentration and CDNC were investigated, while the study of Kivekäs et al. (2009) focused on the role of the particle chemical composition in the observed cloud droplet activation. Also, Anttila et al. (2009) presented a new theoretical framework which was applied to estimate the maximum supersaturation reached in clouds and to provide quantitative estimates for the importance of the particle hygroscopicity and mixing state to the observed cloud droplet activation. However, none of these studies did feature CCN measurements or systematic simulations done with a cloud model.

The goals of the current study are the following: (1) investigate whether aerosol-CCN closure can be reached for the selected cloudy periods, (2) compare CDNC with various aerosol properties and CCN concentrations, (3) provide estimates for the maximum supersaturation and updraft velocity reached in the observed clouds, and (4) assess the relative importance of the vertical velocity, particle size distribution and hygroscopicity to CDNC. The analysis will be done using previously developed modeling tools (Anttila et al., 2009; Anttila, 2010).

\section{Campaign overview}

\subsection{Experimental methods}

The third Pallas Cloud Experiment (PaCE-3) was an intensive one-month measurement campaign for aerosol and cloud properties during 11 September to 11 October 2009. The measurements relevant to this study were conducted by the Finnish Meteorological Institute and by the University of Eastern Finland at the Pallas-Sodankylä Global Atmospheric Watch (GAW) station (Hatakka et al., 2003).

The Pallas-Sodankylä GAW station is located inland near the northern edge of the boreal forest zone. The station consists of several measurement sites, of which only the main Pallas site Sammaltunturi $\left(67^{\circ} 58^{\prime} \mathrm{N}, 24^{\circ} 07^{\prime} \mathrm{E}, 560 \mathrm{~m}\right.$ above sea level) is considered here. This site is located slightly above the tree line on a top of hill Sammaltunturi, which rises about $300 \mathrm{~m}$ above the surrounding area. Sammaltunturi is located at the half way of a north-south oriented chain 
of hills reaching some $500-800 \mathrm{~m}$ in altitude. The area to the east and west of the hills is mainly lowland covered with boreal forest and swamps. The station is located inside the uninhabited Pallas-Yllästunturi national park. Also, the area is very sparsely populated outside the park, and the only municipalities within $50 \mathrm{~km}$ radius from the Sammaltunturi site are Muonio and Kittilä with some 2500 and 6000 inhabitants, respectively.

The measurements were conducted from 11 September to 11 October 2009. This time period of the year was chosen to maximize the chances of the station being inside cloud, even though the fraction of time when the station was inside cloud (visibility below $1000 \mathrm{~m}$ ) turned out to be only $6 \%$ of the time. During the first half of the campaign the air masses arriving to Pallas came from Northern Atlantic. The second half of the campaign was characterized by air masses of Arctic origin, even though sometimes the air had spent several days above land in Northern Scandinavia. The ambient temperature at the $570 \mathrm{~m}$ altitude was on average $1.8^{\circ} \mathrm{C}$ and varied ( $5 \%$ to $95 \%$ values) from $-4.8^{\circ} \mathrm{C}$ to $+9.2^{\circ} \mathrm{C}$ during the campaign period. The temperature was below $0{ }^{\circ} \mathrm{C}$ for $42 \%$ of the time. The winds were mostly western with average (5\% to $95 \%$ values) wind speed of $6.1 \mathrm{~m} \mathrm{~s}^{-1}\left(2.7 \mathrm{~m} \mathrm{~s}^{-1}\right.$ to $12.0 \mathrm{~m} \mathrm{~s}^{-1}$ ). The ambient RH was measured with Vaisala HUMICAP sensor, and visibility and temperature were measured with Vaisala FD12P weather sensor (see Hatakka et al., 2003 for details).

Two differential mobility particle sizers (DMPS) were used to measure the aerosol number size distribution. Both instruments were operated as described by Komppula et al. (2005). One DMPS was attached to a so-called total air inlet, which lets in all particles including cloud droplets (but not rain drops). The cloud droplets were then evaporated, and the dry cloud condensing nuclei were measured among the non-activated particles. The other DMPS was attached to a PM $2.5 \mu \mathrm{m}$ inlet which prevented the cloud droplets from entering the system and hence the DMPS measured only the non-activated particles. Each of the DMPS instruments measured the dry diameter range $7-500 \mathrm{~nm}$ in 30 discrete size fractions. The whole size range was scanned in approximately five minutes by each DMPS, and the data was saved after each cycle. Regarding the experimental uncertainties, it should be noted that the DMPS system is operated according to the GAW standards (Hatakka et al., 2003) and the DMPS measurements are continuously verified against a reference instrument.

Particle hygroscopicity was measured with a HTDMA (Hygroscopicity Tandem Differential Mobilitity Analyzer). The HTDMA has been constructed at the Finnish Meteorological Institute, and consists of four main parts: (1) "Dry" DMA for selecting the dry sizes; (2) aerosol humidifier, which humidifies the sample air to wanted RH; (3) "Wet" DMA, where the humidified aerosol is size-segregated; and (4) a condensation particle counter (TSI CPC 3772), where humidified and size-segregated aerosol concentrations are measured. The HTDMA is constructed to meet the EUSAAR standards for continuous measurements of the aerosol hygroscopicity at a fixed RH (Duplissy et al., 2009). The sample air flow rate in the HTDMA is 1 LPM. Both DMA's work in a closed loop sheath air arrangement, with the "Dry" DMA's sheath flow set at 9LPM and the "Wet" DMA's sheath flow set at 6 LPM. The aerosol is humidified solely in the sample air, using a heated Gore-Tex humidifier, to $\mathrm{RH}=90 \%$. The RH is measured in the "Wet" DMA, located in an insulated housing with the temperature kept $\sim 3^{\circ} \mathrm{C}$ cooler than the lab temperature. The "Wet" DMA's voltages are operated in a scanning mode. This enables the HTDMA to measure 8 dry sizes from $15 \mathrm{~nm}$ to $265 \mathrm{~nm}$ with one full cycle taking about one hour. The proper operation with the HTDMA is verified with dry calibrations (by-passing the humidifier) and ammonium sulfate calibrations. Finally, the HTDMA data is analysed by using the data-inversion toolkit provided by Martin Gysel, Paul Scherrer Institute. The data inversion is described in detail by Gysel et al. (2009).

The Cloud Condensation Nuclei Counter (CCNC, DMT model CCN-100, described by Roberts and Nenes, 2005) was operated at a total flow rate of $0.5 \mathrm{lpm}$ and at five different supersaturations $(0.2,0.4,0.6,0.8$ and $1.0 \%)$, each set for $15 \mathrm{~min}$. Data processing included skipping the first five minutes of data after changing the supersaturation to ensure that the CCNC column was operating at stable conditions. CCNC was calibrated on-site using DMA (short HAUKE type) coupled with a CPC TSI 3010 and Aerosol Generator ATM 226 (Topas $\mathrm{GmbH}$, Germany) with ammonium sulfate solution in a range of temperature differences between 2 and $16^{\circ} \mathrm{C}$ which covers the supersaturation range from about 0.1 to $1 \%$. The total aerosol number concentration $(\mathrm{CN})$ was measured by a condensation particle counter (CPC, TSI model 3772) connected to the same sampling line as the CCNC.

\subsection{Observed cloud events}

Presence of clouds on the measurement site was assessed with the approach taken in the previous study of Komppula et al. (2005). Briefly, a cloud event was judged to have taken place when the following conditions were met at least for an hour: relative humidity stayed around $100 \%$ and visibility was below $1000 \mathrm{~m}$. For the day time periods, photos taken by a web camera located on the site was used for further verification. By these criteria, the measurement site was inside clouds for around $60 \mathrm{~h}$ during the experiment. For further screening of the data we calculated the size distribution of activated particles (cloud residual particles) during the cloud events as described in Anttila et al. (2009). This allows for inferring the fraction of particles that activated into cloud droplets for each DMPS channel from the difference in the particle number concentrations measured through the total and interstitial aerosol inlets. This has been shown to give reliable estimates for the number concentration of cloud droplets (Henning et al., 2002; Komppula et al., 2005). The 
size-resolved uncertainties in the activated fractions were estimated as described in Komppula et al. (2005). Further analysis of size-resolved differences between two DMPS instruments operated in parallel can be found in Wiedensohler et al. (2012).

The acquired data set was further screened according to the following criteria: no rainfall took place during the period and the fraction of activated particles was $>80 \%$ at the diameter range $>400 \mathrm{~nm}$. These criteria were applied for the reasons discussed in our previous cloud campaign study (Anttila et al., 2009, Sect. 4.1). As a final criterion in the selection of the cloud cases it was required that the H-TDMA instrument was running during the cloud event to constrain the particle hygroscopicity in model calculations. The measurement data for the chosen cloud events was averaged using an interval of $105 \mathrm{~min}$. A rather long averaging interval was chosen to ensure that size resolved H-TDMA data and $\mathrm{CCN}$ data are available for each time interval. As a result, the data set analyzed here consists of around $33 \mathrm{~h}$ of measurements with five prominent cloud events.

\section{Modeling approach}

We performed CCN closure calculations and model simulations with an air parcel model. Both of these approaches require extrapolation of the measured hygroscopic growth factors to cover the particle size range scanned by the DMPS instrumentation. Therefore the extrapolation method will be described first (Sect. 3.1), followed by a description of the performed CCN calculations (Sect. 3.2) and cloud model simulations (Sect. 3.3).

\subsection{Treatment of the particle hygroscopicity}

A log-normal function was fitted to each humidified particle size distribution to parameterize the particle hygroscopic properties. The performance of the fit was evaluated and it was concluded that the data can be adequately described by a single log normal function. In other words, only a single hygroscopic mode was generally present which indicates a low degree of external mixing among the sampled particles. For each measured distribution, a mean hygroscopic growth factor ( $\mathrm{HGm})$ and general standard deviation (GSD), indicative of the width of the distribution, was thereby obtained for each time interval and each dry particle size measured by H-TDMA. Here we follow the approach of our previous study where it was assumed that distribution of hygroscopic growth factors can be described by a log normal function across the particle size spectrum (Anttila et al., 2009). Accordingly the hygroscopic parameters HGm and GSD were fitted with a function of the form $f(x)=a x^{b}$, where $x$ is the particle dry diameter, and $a$ and $b$ are the fitting parameters. The fitting was done separately for each full cycle of H-TDMA data. To verify the accuracy of the fitting process, the experimental values of these parameters were compared to those given by the corresponding fit function for each dry size measured with the H-TDMA instrument. The average error in the mean HG factor varied between one and five percent and was one percent at maximum in the case of GSD. This demonstrates that the fit could be performed successfully with the chosen form of the function. Also, the extrapolated values stayed within a physically reasonable range for the considered dry size interval $(50-400 \mathrm{~nm})$. Here we do not illustrate the fitting procedure with figures, but we refer to our previous work where similar procedure was applied (Anttila et al., 2009; Anttila 2010).

\subsection{CCN closure calculations}

The CCN concentration at a supersaturation $s, \operatorname{CCN}_{\text {tot }}(s)$, was calculated using the following equation (Eq. (7) in Anttila et al., 2009):

$\mathrm{CCN}_{\text {tot }}(s)=\sum_{i=1}^{N} \mathrm{AF}_{i}(s) \mathrm{CN}_{\text {tot }, i}$.

Here the summation is taken over DMPS size channels and thus $\mathrm{N}$ is the number of the channels. Also, $\mathrm{AF}_{i}(s)$ is the fraction of particles, having a dry size corresponding to channel $i$, that are predicted to be activated at the supersaturation $s$, and $\mathrm{CN}_{\text {tot, } \mathrm{i}}$ is the total particle number concentration in the channel $i$. The functions $\mathrm{AF}_{i}$ are calculated according to Eq. (5) in Anttila et al. (2009). To summarize the process, hygroscopic distributions for each size class $i$ (obtained by the fitting procedure described in the previous section) are converted to the corresponding distributions of particle critical supersaturations through the use of the Koehler theory. For the details regarding the Koehler theory, a good overview is given in the review article of McFiggans et al. (2006). Underlying assumption behind the approach is that the width of the measured HG factor distribution for a given particle dry size reflects the variance in chemical composition (hygroscopicity) of the sampled aerosols. This assumption can be considered as reasonable as argued in Anttila et al. (2009) (Sect. 4.2). What comes to the other inputs for Eq. (1), the values of $\mathrm{CN}_{\mathrm{tot}, i}$ are taken from the DMPS total inlet measurements, and the particle surface tension was assumed to be that of water. It should be noted that the current approach accounts for the particle mixing state and size dependence of the particle hygroscopicity. More details of the method can be found in Sect. 2.1 in Anttila et al. (2009).

\subsection{Cloud model simulations}

Cloud model simulations were performed in order to investigate the relative importance of the meteorology, particle physical properties and hygroscopicity on the observed cloud droplet concentrations. Here we have applied a previously developed model described in detail in Anttila (2010). Briefly, the model simulates the time development of an 
Table 1. Observed features of the analyzed cloud events. For each event, an average value of the quantity is shown, followed by the ranges in parentheses which represent the minimum and maximum values. Here $\mathrm{CN}_{\text {tot }}$ is the total particle number concentration, $\mathrm{CN}(>100 \mathrm{~nm})$ is the concentration of particles with dry sizes above $100 \mathrm{~nm}, \mathrm{CMD}$ is the count mean diameter of the size distribution, CDNC is the inferred number of cloud droplets and $D_{50}$ is the diameter corresponding to the $50 \%$ activation efficiency. Moreover, estimated hygroscopic growth factors at $90 \% \mathrm{RH}$ for particles having a dry size of $100 \mathrm{~nm}, G f(100 \mathrm{~nm})$, are shown along with the corresponding values of the hygroscopicity parameter $\kappa$ (calculated according to Petters and Kreidenweis, 2007), $\kappa(100 \mathrm{~nm})$. The values of $\kappa$ were calculated at temperature of $298 \mathrm{~K}$ and under the assumption that the droplet surface tension equals that of water.

\begin{tabular}{lccccc}
\hline Case & $\mathrm{A}$ & $\mathrm{B}$ & $\mathrm{C}$ & $\mathrm{D}$ & $\mathrm{E}$ \\
\hline Time period & 9.9. & 22.9. & $22 .-23.9$. & $25 .-26.9$. & 4.10. \\
& $08: 00-13: 45$ & $06: 45-08: 15$ & $22: 30-08: 30$ & $23: 30-04: 15$ & $01: 30-12: 15$ \\
\hline $\mathrm{CN}_{\text {tot }}\left(\mathrm{cm}^{-3}\right)$ & $531(389-532)$ & 1518 & $449(325-768)$ & $385(339-434)$ & $499(321-1141)$ \\
$\mathrm{CN}(>100 \mathrm{~nm})\left(\mathrm{cm}^{-3}\right)$ & $127(56-242)$ & 131 & $100(82-125)$ & $29(14-46)$ & $119(74-226)$ \\
$\mathrm{CMD}(\mathrm{nm})$ & 76 & 59 & 68 & 45 & 74 \\
$\mathrm{CDNC}\left(\mathrm{cm}^{-3}\right)$ & $93(43-168)$ & 97 & $89(72-105)$ & $49(41-56)$ & $99(79-125)$ \\
$D_{50}(\mathrm{~nm})$ & $101(98-106)$ & 98 & $92(86-97)$ & $80(78-81)$ & $102(79-125)$ \\
Activated fraction & $0.17(0.09-0.22)$ & 0.06 & $0.22(0.09-0.29)$ & $0.13(0.11-0.17)$ & $0.23(0.13-0.37)$ \\
Temperature $\left({ }^{\circ} \mathrm{C}\right)$ & 9.1 & 2.4 & 4.9 & 5.0 & -3.2 \\
Visibility $(\mathrm{m})$ & 149 & 207 & 138 & 142 & 120 \\
$\mathrm{Gf}(100 \mathrm{~nm})$ & $1.24(1.21-1.26)$ & 1.14 & $1.15(1.14-1.18)$ & $1.17(1.14-1.21)$ & $1.26(1.17-1.31)$ \\
$\kappa(100 \mathrm{~nm})$ & $0.12(0.10-0.13)$ & 0.06 & $0.07(0.06-0.09)$ & $0.08(0.06-0.09)$ & $0.13(0.08-0.16)$ \\
\hline
\end{tabular}

aerosol/droplet population in a homogeneous air parcel that ascends with a constant velocity $V$. The aerosols are divided into sections according to both their size and hygroscopicity. The model was initialized using the aerosol distributions measured through the total inlet and hygroscopic growth parameters were determined according to the method described in Sect. 3.1. In particular, the particle size range was discretized into classes so that the dry diameters matched the nominal diameters of the DMPS channels. As in the case of $\mathrm{CCN}$ calculations, the droplet surface tension was assumed to be equal to that of water, and the mass accommodation coefficient of water vapour was set equal to unity.

Due to the nature of the campaign set up, it is not possible to determine exactly the meteorological conditions under which the observed clouds were formed. For this reason, the temperature at the cloud base was simply assumed to be the same as the average measured temperature at the site for each cloud period. This is rather unimportant assumption because the preliminary calculations showed that the results are only weakly sensitive to the initial temperature compared to the assumed value of the updraft velocity. Because of uncertainties regarding the formation history of the observed clouds, the updraft velocity was treated as a free parameter. Hence we cannot perform such a strict closure study as in the case of aerosol-CCN relationships. Instead, we use the model as a diagnostic tool for evaluating the relative roles of different factors played in the cloud formation. This will be discussed in more detail in Sect. 6.

The model simulations were run with a time step of a second and the output was recorded at the instant when the water vapour supersaturation reached its maximum in the air parcel. The main outputs of the model are the total number of cloud droplets formed, the activated fraction of particles for each size class and the maximum supersaturation of water vapour. In particular, the diameters corresponding to the $50 \%$ activation efficiency, $\mathrm{D}_{50}$, were interpolated from the results to establish comparison with the experimental values of $D_{50}$.

\section{Observed features of the cloud events}

\subsection{Relationships between aerosol properties and cloud activation characteristics}

Table 1 summarizes the key features of the considered cloud events which consist of around $33 \mathrm{~h}$ of measurement data. Here we have denoted the events with Latin alphabets from A to $\mathrm{E}$. The shortest event in duration, case B, covered only a single averaging interval while the longest case $E$ lasted for around $11 \mathrm{~h}$ and $45 \mathrm{~min}$. The average total particle concentrations, $\mathrm{CN}_{\text {tot }}$, varied from 385 to $1518 \mathrm{~cm}^{-3}$ between the events. Compared to longer data series analyzed in Tunved et al. (2003), this value range can be considered as typical for the site. Table 1 shows further that particles with dry diameters above $100 \mathrm{~nm}, \mathrm{CN}(>100 \mathrm{~nm})$, made only a small contribution to the total number concentrations: the ratio between $\mathrm{CN}_{\text {tot }}$ and $\mathrm{CN}(>100 \mathrm{~nm})$ varied in the range 0.06 to 0.25 , implying that Aitken mode sized particles dominated the total particle number concentrations. Largest differences in the particle size distributions were found between the events $B$ and $\mathrm{D}$, so that that the particle size distribution featured a prominent Aitken mode during the event B whereas there were only a few tens of particles were in the accumulation 


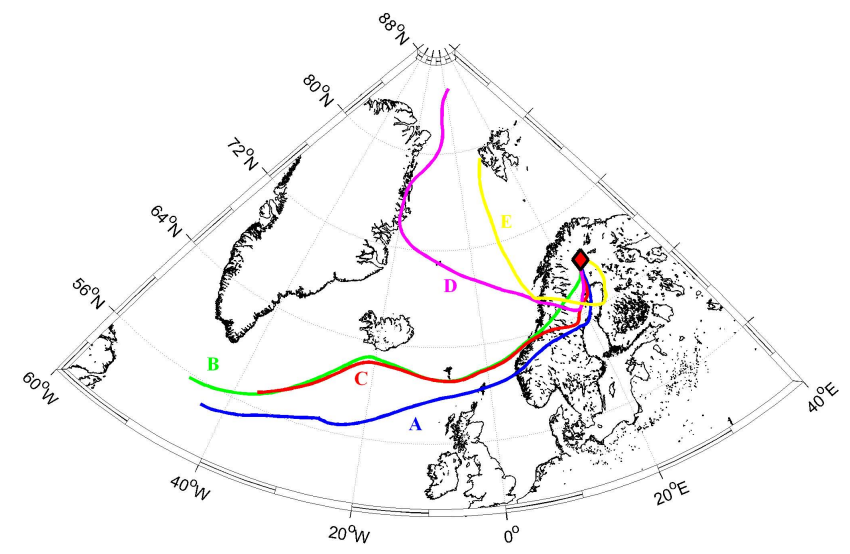

Fig. 1. 72-h back trajectories for each analyzed cloud event (indicated in the figure).

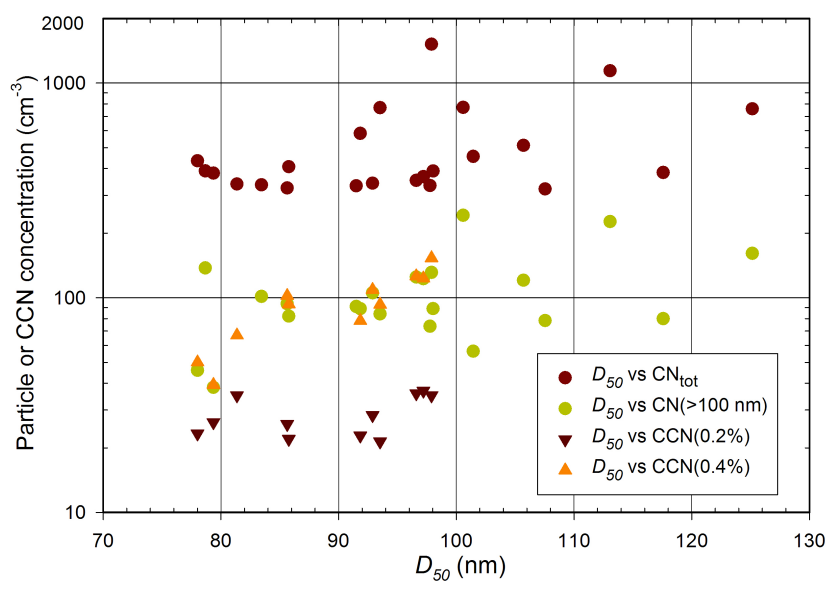

Fig. 2. The diameter corresponding to $50 \%$ activation efficiency $\left(D_{50}\right)$ versus particle and $\mathrm{CCN}$ concentrations (indicated in the legend).

mode sizes during the event $\mathrm{D}$. In order to elucidate reasons behind such differences, we evaluated the air mass history by calculating the 5-day back trajectories with the HYSPLIT model (Draxler and Rolph, 2012), shown in Fig. 1. As seen, the air masses can be roughly into two groups: those originating from North-East Atlantic (events A, B and C) and those from Arctic Ocean (events D and E). On average, the air masses from North-East Atlantic featured smaller particle concentrations than those originating from Arctic region which is probably explained by a lower level of pollution in northern air masses.

Table 1 shows further that the average number of cloud droplets inferred from the dual-DMPS setup, CDNC, varied between 49 and $99 \mathrm{~cm}^{-3}$. Such numbers are somewhat smaller than the average numbers obtained from an analysis of a longer data set from the site (Komppula et al., 2005) and are also generally smaller than observed in the previous campaign, PaCE-2 (Anttila et al., 2009). Also, the average value

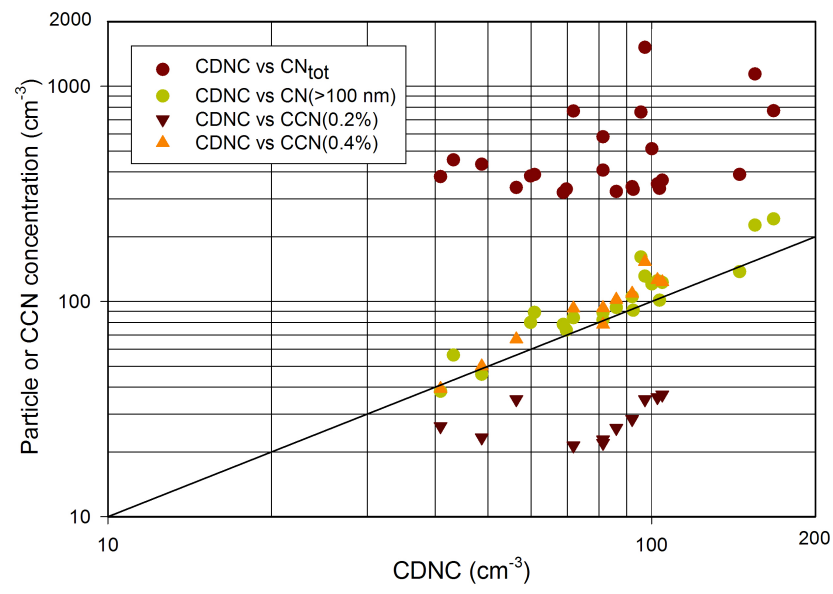

Fig. 3. Cloud droplet concentration (CDNC) versus particle and $\mathrm{CCN}$ concentrations (indicated in the legend). A 1:1 line is included as a guide to the eye.

of the diameter at which $50 \%$ of the particles are activated into cloud droplets, $D_{50}$, varied in the range 80 to $102 \mathrm{~nm}$ between the cases. These numbers are slightly lower than observed in the previous campaign (Anttila et al., 2009) but compare well to those reported by Komppula et al. (2005). Results from other sites suggests that the $D_{50}$ values fall generally into the range between 100 and $150 \mathrm{~nm}$ (Henning et al., 2002 and references therein; Mertes et al., 2005). Figure 2 shows the correlation between $D_{50}$ and $\mathrm{CN}_{\text {tot }}$ as well as between $D_{50}$ and $\mathrm{CN}(>100 \mathrm{~nm})$. No visible correlation can be seen which suggests that the observed variation in $D_{50}$ was not driven by the aerosol number concentrations.

Overall, comparing the corresponding values of $\mathrm{CN}(>100 \mathrm{~nm}), \mathrm{CDNC}$ and $D_{50}$, it can be concluded that Aitken mode particles made only a small contribution to the number of activated cloud droplets. This is further illustrated Figs. 3 and 4: Fig. 3 shows the correlation between $\mathrm{CDNC}$ and $\mathrm{CN}(>100 \mathrm{~nm})$ while Fig. 4 illustrates the average and overall variation of these quantities for each cloud event. Conversely, $\mathrm{CN}_{\text {tot }}$ and $\mathrm{CDNC}$ do not show any visible correlation (Fig. 3) which further emphasizes the dominant role of accumulation mode particles played in the observed variation in CDNC. This finding is consistent with the previous cloud observations done at the site (Komppula et al., 2005). As also seen from Fig. 3, the relationship between $\mathrm{CDNC}$ and $\mathrm{CN}(>100 \mathrm{~nm})$ is approximately linear. This is in contrast with many other empirical data sets where sublinear correlation between CDNC and accumulation mode sized particles is found (see e.g. Fig. 5 in Lihavainen et al., 2008, and Fig. 10 in Kleinman et al., 2012). As noted above, CDNC varied over a relatively small interval in the cloud cases considered here while the data sets displayed in the aforementioned studies cover a larger range of conditions. Also, the air masses sampled here were relatively clean while the "suppression effect", i.e. nonproportional increase 


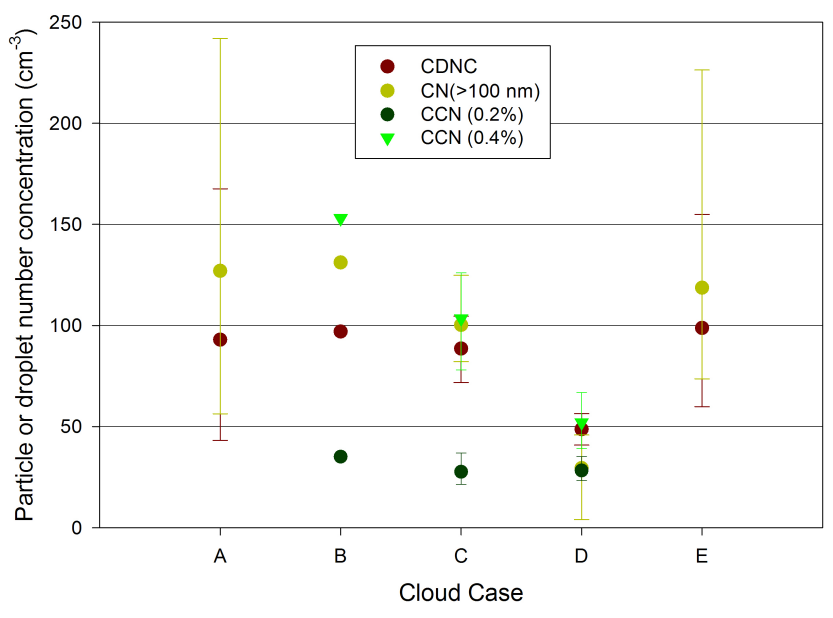

Fig. 4. The comparison of the cloud droplet concentrations (CDNC), the number concentrations of particles with dry diameter above $100 \mathrm{~nm}, \mathrm{CN}(>100 \mathrm{~nm})$, and $\mathrm{CCN}$ concentrations at supersaturations 0.2 and $0.4 \%$ for each cloud case. Here the symbols represent average values and the bars indicate the range over which the quantity varied during the event.

in CDNC as a response to increasing aerosol concentrations, is more characteristic to polluted air masses (e.g. Reutter et al., 2009).

\subsection{Particle hygroscopicity measurements}

Table 1 shows the interpolated particle hygroscopic growth factors of particles with a dry diameter of $100 \mathrm{~nm}$, Gf $(100 \mathrm{~nm})$. These values were calculated using the fit functions described in Sect. 2 to interpolate the growth factors to $100 \mathrm{~nm}$ and averaging the results over the duration of an event. We report interpolated values to provide a compact characterization of the particle hygroscopicity at a diameter close to typical values of $D_{50}$. As seen, the average values Gf $(100 \mathrm{~nm})$ for each cloud cases varied between 1.14 and 1.26. These values are comparable to the results of the previous campaign, PaCE-2 (Table 3 in Kivekäs et al., 2009).

Petters and Kreidenweis (2007) introduced a dimensionless parameter $\kappa$ to characterize the particle hygroscopicity and CCN activity. This has become a widely used parameter in the field and to facilitate comparisons with other studies, we converted $\mathrm{Gf}(100 \mathrm{~nm})$ to the corresponding values of $\kappa, \kappa$ $(100 \mathrm{~nm})$. The case-averaged values of $\kappa(100 \mathrm{~nm})$ varied between 0.06-0.13 (Table 1). For comparison, Kammermann et al. (2010) reported an average value of 0.16 for $\kappa$ for particles with a dry size of $110 \mathrm{~nm}$ in a campaign that took place in a subarctic site in northern Sweden while Cerully et al. (2011) and Sihto et al. (2012) derived $\kappa$ values of $0.1-0.15$ and 0.18 , respectively, from H-TDMA measurements conducted at a boreal site in middle part of Finland. Also, Andreae and Rosenfeld (2008) concluded that a $\kappa$ value range of $0.2-0.4$ is a good approximation for the hygroscopicity of continen-

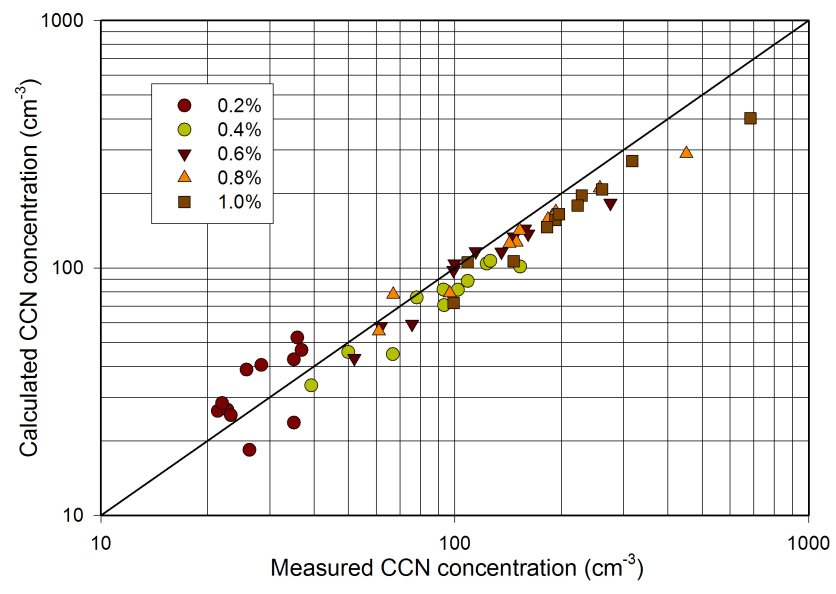

Fig. 5. Measured versus calculated $\mathrm{CCN}$ concentrations. A 1:1 line is added as a guide to the eye.

tal aerosols, while the value of $\kappa$ for continental aerosols varied mainly in the range of $0.1-0.4$ in the global modeling study of Pringle et al. (2010). These comparisons show that the aerosols observed during the current campaign were notably less hygroscopic than what has been typically observed for continental background aerosols. In fact, such low values of $\kappa$ are consistent with the notion that the observed aerosols were mainly comprised of organic compounds (Levin et al., 2012). The particle chemical composition was measured with an aerosol mass spectrometer (AMS, DeCarlo et al., 2006) instrument during the campaign, and the results will be presented in a separate publication (Jaatinen et al., 2012). Here it suffices to note that the AMS instrument was running only during the cloud events $\mathrm{C}$ and $\mathrm{D}$, and the average mass fractions of sulphate were $10 \%$ and $9 \%$ during these events, respectively, while the rest of the particulate matter was composed mainly of organic compounds or some other compounds that were not detected by AMS. These results support the notion that large organic mass fraction explains the low particle hygroscopicity observed during the events.

\subsection{Relationships between $\mathrm{CCN}$ and cloud activation characteristics}

Measured CCN concentrations are shown in Table 2 for each supersaturation applied in the $\mathrm{CCN}$ counter. For the cases A and $\mathrm{E}$, the $\mathrm{CCN}$ measurement instrument was not operating during the cloud event and hence no numbers are given for these cases. We compared our observations with those reported by Kammermann et al. (2010) who performed CCN measurements at a subarctic site in northern Sweden. For the supersaturations of 0.20 and $0.4 \%$ which overlap with the supersaturations applied in our study, Kammermann reported average CCN concentrations of 212 and $312 \mathrm{~cm}^{-3}$, respectively (see Table 1 of the aforementioned study). As seen from Table 2 of the present study, these numbers are 
Table 2. Measured and calculated CCN concentrations averaged over the duration of an event. The minimum and maximum values are shown in parenthesis.

\begin{tabular}{lccccc}
\hline Case & $\mathrm{A}$ & $\mathrm{B}$ & $\mathrm{C}$ & $\mathrm{D}$ & $\mathrm{E}$ \\
\hline \multicolumn{7}{c}{ Experimental results } \\
\hline $\mathrm{CCN}(0.2 \%)$ & $\mathrm{n} / \mathrm{a}$ & 35 & $28(21-37)$ & $28(23-35)$ & $\mathrm{n} / \mathrm{a}$ \\
$\mathrm{CCN}(0.4 \%)$ & $\mathrm{n} / \mathrm{a}$ & 153 & $103(78-126)$ & $52(39-67)$ & $\mathrm{n} / \mathrm{a}$ \\
$\mathrm{CCN}(0.6 \%)$ & $\mathrm{n} / \mathrm{a}$ & 275 & $131(99-161)$ & $63(52-76)$ & $\mathrm{n} / \mathrm{a}$ \\
$\mathrm{CCN}(0.8 \%)$ & $\mathrm{n} / \mathrm{a}$ & 451 & $181(143-257)$ & $75(61-97)$ & $\mathrm{n} / \mathrm{a}$ \\
$\mathrm{CCN}(1.0 \%)$ & $\mathrm{n} / \mathrm{a}$ & 684 & $229(182-318)$ & $118(99-147)$ & $\mathrm{n} / \mathrm{a}$ \\
\hline \multicolumn{7}{c}{ Model results, calculated at $25^{\circ} \mathrm{C}$} & \\
\hline $\mathrm{CCN}(0.2 \%)$ & $86(34-171)$ & 43 & $37(26-52)$ & $23(18-25)$ & $76(50-112)$ \\
$\mathrm{CCN}(0.4 \%)$ & $139(63-269)$ & 101 & $87(71-107)$ & $41(34-46)$ & $122(86-195)$ \\
$\mathrm{CCN}(0.6 \%)$ & $189(101-348)$ & 183 & $121(98-144)$ & $54(43-59)$ & $168(124-290)$ \\
$\mathrm{CCN}(0.8 \%)$ & $240(145-419)$ & 289 & $156(156-210)$ & $71(56-79)$ & $215(164-380)$ \\
$\mathrm{CCN}(1.0 \%)$ & $284(184-477)$ & 402 & $188(146-270)$ & $95(72-106)$ & $257(196-462)$ \\
\hline \multicolumn{7}{c}{ Model results, calculated at ambient temperature } & \\
\hline $\mathrm{CCN}(0.2 \%)$ & $82(32-162)$ & 37 & $31(22-45)$ & $20(16-23)$ & $66(32-101)$ \\
$\mathrm{CCN}(0.4 \%)$ & $133(60-258)$ & 88 & $81(66-101)$ & $39(32-44)$ & $109(76-167)$ \\
$\mathrm{CCN}(0.6 \%)$ & $180(94-333)$ & 155 & $113(91-129)$ & $50(41-55)$ & $147(106-250)$ \\
$\mathrm{CCN}(0.8 \%)$ & $228(135-402)$ & 244 & $144(117-188)$ & $64(51-71)$ & $188(140-330)$ \\
$\mathrm{CCN}(1.0 \%)$ & $272(174-460)$ & 346 & $175(137-245)$ & $83(65-93)$ & $227(173-406)$ \\
\hline
\end{tabular}

clearly higher than measured in our campaign. We speculate that the difference is mainly due to two factors: we observed generally lower particle number concentrations and less hygroscopic particles (see Sect 1.2 above and Table 1 in Kammermann et al., 2010). We do not pursue the topic further here, however, as the CCN measurements will be presented in more detail in a separate paper (Jaatinen et al., 2012). Instead, we focus here on comparing the $\mathrm{CCN}$ and cloud activation measurements and present the $\mathrm{CCN}$ closure only for the analyzed cloudy periods. Extensive $\mathrm{CCN}$ closure covering the whole campaign will be presented by Jaatinen et al. (2012).

The CCN concentrations for the smallest two applied supersaturations, $\mathrm{CCN}(0.2 \%)$ and $\mathrm{CCN}(0.4 \%)$, are compared with the inferred cloud droplet concentrations in Fig. 3 for each cloud case during which the $\mathrm{CCN}$ counter was operating. As can be seen, CDNC values fell generally between the $\mathrm{CCN}(0.2 \%)$ and $\mathrm{CCN}(0.4 \%)$ so that $\mathrm{CCN}(0.4 \%)$ often approximates nicely the corresponding value of CDNC. The good degree of correlation between $\mathrm{CDNC}$ and $\mathrm{CCN}(0.4 \%)$ is further illustrated in Fig. 3. These findings suggest that that the "effective" maximum supersaturation, $s_{\max }$, in the observed clouds was around $0.4 \%$ in most of the cases. In comparison, inferred values of $s_{\max }$ varied between 0.18 and $0.26 \%$ during the previous cloud campaign on the site (Anttila et al., 2009). Also a supersaturation level of $0.4 \%$ is considerably larger than those reported in previous ground based particle activation studies (Sveningsson et al., 1994; 1997, Martinsson et al, 1999; Mertes et al., 2005). Unfor- tunately, the $\mathrm{CCN}$ instrument was not operating during the cloud events $\mathrm{A}$ and $\mathrm{E}$, but we will present model based estimates for $s_{\max }$ for all the considered cloud events in Sect. 6 .

The correlations of $\mathrm{CCN}(0.2 \%)$ and $\mathrm{CCN}(0.4 \%)$ with $D_{50}$ are shown in Fig. 2. As seen, $\mathrm{CCN}(0.4 \%)$ correlates positively with $D_{50}$, the coefficient of determination being 0.78 , while no clear correlation can be found between $\mathrm{CCN}(0.2 \%)$ and $D_{50}$. This can be interpreted so that larger numbers of $\mathrm{CCN}$ active particles led to decreased activation efficiency due to competition between particles for water vapour during the cloud formation. However, the data set is limited because there are no CCN measurements available for the cloud cases $\mathrm{A}$ and $\mathrm{E}$, and thus the result could be caused by poor statistics. To investigate this further we estimated $\mathrm{CCN}(0.4 \%)$ concentrations for the cloud cases $\mathrm{A}$ and $\mathrm{E}$ with the model described in Sect. 3.2. The results show that when the estimated $\mathrm{CCN}$ concentrations are included in the comparison, correlation between $\mathrm{CCN}(0.4 \%)$ and $D_{50}$ reduces considerably so that the coefficient of correlation is 0.03 . Therefore no clear conclusions can be drawn on the basis of the available measurement results but larger data sets are needed to investigate the issue.

\section{CCN closure for the cloud periods}

A first phase of the modeling work was to find out if the observed CCN concentrations can be predicted on the basis of the Koehler theory using the observed size distributions 
and extrapolated hygroscopic growth properties as input. The motivation for this is to test our understanding on the factors determining the particle $\mathrm{CCN}$ activation efficiency and also to pave way for the simulations made with the air parcel model.

The CCN concentrations were calculated as described in Sect. 3.2 for each supersaturation applied in the measurements and for each time interval for which $\mathrm{CCN}$ data were available. The results are summarized in Fig. 5. As seen, the overall correlation is rather good, the average absolute relative errors being $30,18,12,16$ and $20 \%$ for the supersaturations $0.2,0.4,0.6,0.8$ and $1.0 \%$, respectively. The corresponding relative bias were $18,-18,-11,-13$ and $-20 \%$ for the supersaturations $0.2,0.4,0.6,0.8$ and $1.0 \%$, respectively, implying that the $\mathrm{CCN}$ concentrations are underpredicted for supersaturations above $0.2 \%$. These numbers were put in context of experimental uncertainties by calculating the standard deviations of the $\mathrm{CCN}$ number counts over each averaging interval and comparing them to the respective total CCN number counts. To summarize, the experimental uncertainties estimated this way were $44,17,15,14$ and $11 \%$ for supersaturations $0.2,0.4,0.6,0.8$ and $1.0 \%$, respectively. Hence the calculated and measured CCN concentrations are generally within the experimental uncertainties excluding the results at $1.0 \%$ supersaturation. These uncertainties aside, the discrepancies could be caused by the presence of slightly soluble compounds in particles that increase the hygroscopicity by dissolving at higher RHs when particles contain more water. As discussed in Sect. 4.2, tentative results show that the particles were dominantly composed of organic compounds, and some of the organics found in atmospheric aerosols are slightly soluble (McFiggans et al., 2006). Because the CCN calculations are partially based on extrapolating hygroscopic measurements done at $90 \% \mathrm{RH}$, possible presence of slightly soluble compounds dissolving at higher RHs cannot be accounted for. Another explanation is that the degree of non-ideality of the particle aqueous phase decreased with increasing supersaturaturation (due to increased dilution) so that the CCN activation ability of particles was enhanced at higher supersaturations. While this remains speculation as the exact identity of the compounds making up the sampled particles remains largely unknown, recent laboratory studies support the notion that the hygroscopicity of particles consisting of atmospherically relevant compounds may vary with varying RH (Wex et al., 2008; Ruehl et al., 2010).

\section{Cloud model simulations}

An open question related to the clouds observed on the measurement site is their formation history: where and under which conditions the clouds were formed and how important were these meteorological conditions in determining the cloud microphysical properties? Towards answering these questions, we did model calculations to see if it is possible to reproduce the observed size dependent activation profiles with an adiabatic air parcel model (Sect. 6.1) and further performed a sensitivity study to investigate the relative importance of meteorology and aerosol properties to the cloud formation (Sect. 6.2). The model uses also the Koehler theory, and the critical supersaturations are calculated on the basis of the H-TDMA data (Sect. 3.3). This approach was found to explain the $\mathrm{CCN}$ activity of the particles quite accurately (Sect. 5). However, as discussed in Sect. 3.3, the updraft velocity was kept as a free parameter due to the lack of relevant measurements. It should be noted that the subsequent results are based on the assumption that the observed clouds were formed under adiabatic conditions even though there is no direct empirical proof of this. Hence the estimated updraft velocities are interpreted here as a measure for the convective activity in the observed clouds rather than a strict estimate for the updraft velocities reached during the cloud formation.

\subsection{Base case simulations}

The updraft velocity was estimated for each averaging time interval in the analyzed data set as follows. For each case, a set of simulations was performed with varying values of updraft velocities so that the velocity range $0.1-1.0 \mathrm{~m} \mathrm{~s}^{-1}$ was covered with an interval of $0.05 \mathrm{~m} \mathrm{~s}^{-1}$. Smaller intervals did not lead to notable improvement due to the fact that particle size distribution is discretized to a finite number of bins. The "representative" updraft velocity was then estimated by choosing the value which minimizes the difference between experimental and modeled cloud droplet number concentrations. The relative error in CDNC was around $3 \%$ on average and $10 \%$ at maximum. Also, Table 3 shows the average values of modeled CDNC for each cloud event which are seen to compare well with the corresponding experimental values displayed in Table 1. We note that the estimated updraft velocities depend also on the choice of the mass accommodation coefficient of water, $\alpha$, which is uncertain to some extent (Laaksonen et al., 2005). Performed sensitivity studies showed that when the optimal values for $V$ decreased consistently by around $25 \%$ when using the lower limit for the value of $\alpha$ (which is 0.04 ). This we take to be the maximum uncertainty caused by $\alpha$. However, the conclusions presented below are robust with respect to the value of $\alpha$ and hence we report the results only for the base case simulations.

The performance of the model was evaluated by comparing the measured and calculated size resolved activation profiles (Fig. 6) and the $D_{50}$ diameters (Fig. 7). From Fig. 6 it can be seen that the predicted and experimental activated fractions were generally within the measurement uncertainties, the agreement being especially good for cases D and E. However, for the rest of the cases, the activated fractions were generally underpredicted at the size range below $\sim 120 \mathrm{~nm}$, while the trend was opposite at the larger sizes. These results seem to suggest that the model tends to overestimate $D_{50}$ 


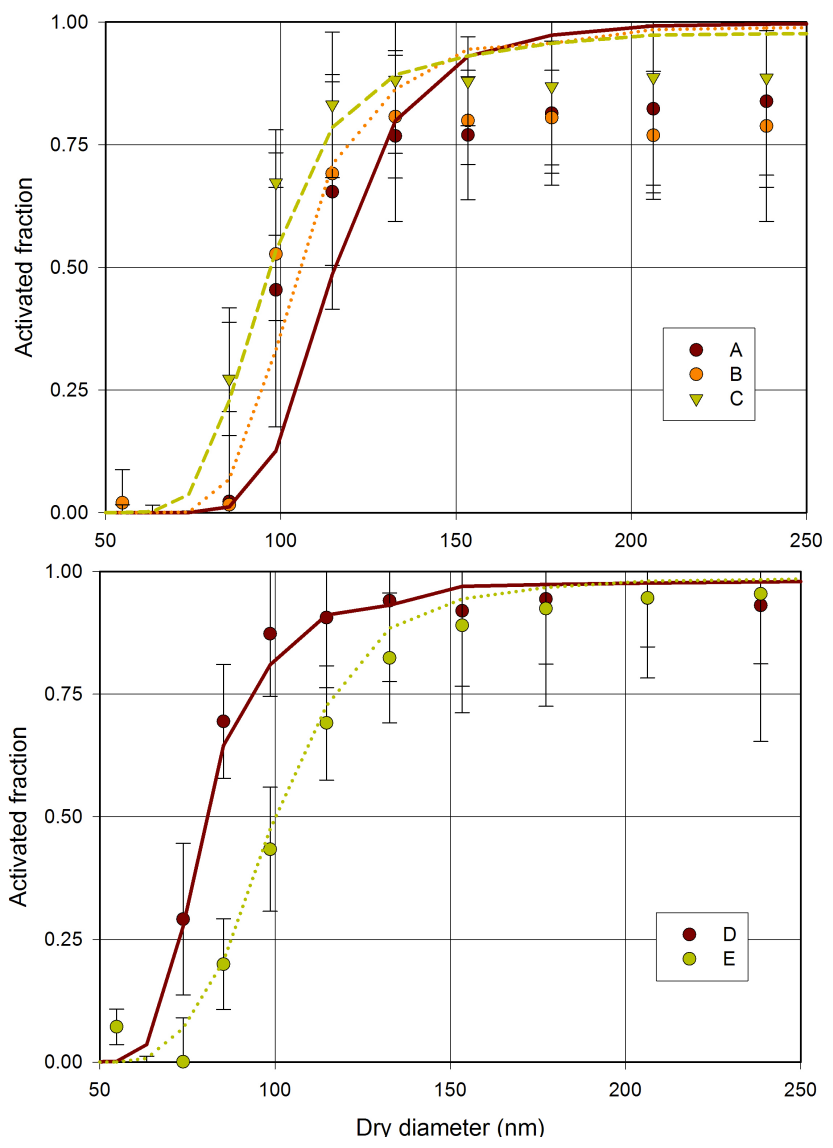

Fig. 6. The measured (symbols) and calculated (lines) activated fractions of aerosols as a function of the particle dry diameter for each cloud event (indicated in the legend). To ease the presentation, the events $\mathrm{A}-\mathrm{C}$ and $\mathrm{D}-\mathrm{E}$ are shown in separate plots.

as compared to experimental results, and this is confirmed by taking a look at the whole data set (Fig. 7). On average, the values of $D_{50}$ were overpredicted by around $5 \%$ by the model. Closer comparison of the experimental and modeling results showed that the model underestimates the activated fractions by around $18 \%$ on average in the diameter range $75-125 \mathrm{~nm}$ while overpredicting the activation fractions by around $8 \%$ on average at the size range $>125 \mathrm{~nm}$ (not illustrated here). This translates to corresponding biases in the size resolved CDNC so that the total CDNC values were reproduced despite these errors. A possible reason for the biases could be corresponding biases in the estimated particle hygroscopicity but this is excluded as no such biases were found when comparing the fitted and experimental hygroscopic growth factors (Sect. 3.1). While the reason for the biases remains uncertain, these errors are comparable to the uncertainties in the experimental activated fractions of which average values varied in the range of 5 to $15 \%$ between the cloud events.

Good agreement between observations and modeling results for the cloud cases D and E seem to imply that the

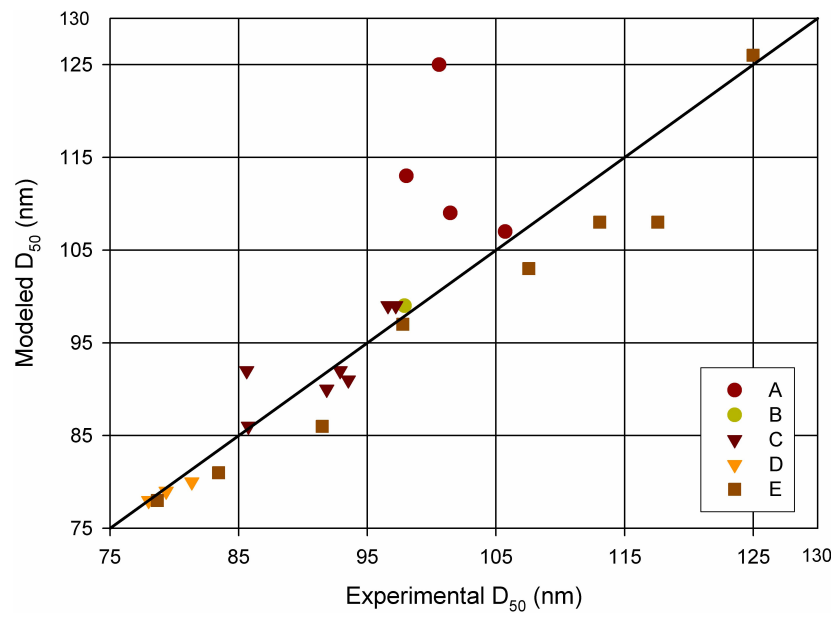

Fig. 7. Same as Fig. 5 but for the diameter $D_{50}$.

Table 3. Summary of the modeling results for each cloud case. Numbers shown are the average values. Here the $\sigma(V)$ is the standard deviation of the updraft velocity. No standard deviation is given for the event $\mathrm{B}$ as it covered only a single averaging interval.

\begin{tabular}{lccccc}
\hline & \multicolumn{5}{c}{ Cloud event } \\
\cline { 2 - 6 } & A & B & C & D & E \\
\hline CDNC $\left(\mathrm{cm}^{-3}\right)$ & 93 & 98 & 88 & 49 & 98 \\
$D_{\mathbf{5 0}}(\mathrm{nm})$ & 115 & 105 & 98 & 80 & 102 \\
$V\left(\mathrm{~m} \mathrm{~s}^{-1}\right)$ & 0.20 & 0.45 & 0.51 & 0.60 & 0.34 \\
$\sigma(V)\left(\mathrm{m} \mathrm{s}^{-1}\right)$ & 0.048 & - & 0.080 & 0.10 & 0.18 \\
$s_{\max }(\%)$ & 0.27 & 0.43 & 0.47 & 0.63 & 0.33 \\
\hline
\end{tabular}

shape of the activation curve is explained by the external mixing of the aerosol, while updraft velocity fluctuations had a marginal broadening effect on the activation curve. This should be interpreted with caution, however, because more information on the origins of the observed clouds along with detailed modeling tools are required to address the issue. With the current zero dimensional model, we cannot account for the effects of the updraft velocity variations in clouds or simulate the activation behavior resulting from mixing of different cloudy air masses with different supersaturation histories. Hence the role of velocity variations on the observed activation behavior remains open. A second feature worth noting is that despite rather large experimental uncertainties, the observational activated fractions seem to reach a "plateau" at the diameter range above $150 \mathrm{~nm}$ in the cloud cases A, B and C. Experimental uncertainties aside, such plateaus can either be caused by entrainment or by evaporation of cloud droplets due to the Bergeron-Wegener-Findeisen process in mixed phase clouds (Henning et al., 2004; Verheggen et al. 2007). However, we have no experimental measurements to assess the role of these processes, and simulating them would need additional information as well. For example, including 


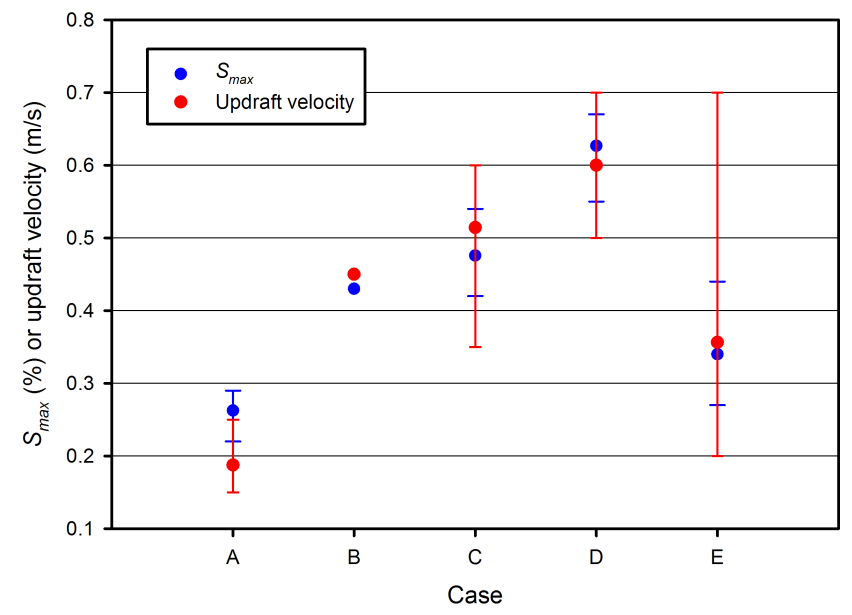

Fig. 8. Calculated maximum supersaturation and the estimated updraft velocity for each cloud event. The symbols represent average values and the bars indicate the minimum and maximum values of the quantity during the event.

entrainment into the model requires measurements on the vertical profile of the liquid cloud water to constrain the needed parameters (Morales et al., 2011). As such, it suffices to note that entrainment decreases the fraction of activated particles throughout the size range (Noone et al., 1992) and thus activated fractions at lower sizes would not match the observations if the model was modified to account for the process. Regarding Bergeron-Wegener-Findeisen process, the temperature measurements indicate that temperature was slightly below zero degrees in Celsius at minimum during the cloudy periods at the station (Table 1), and hence the observed clouds contained probably only liquid water (Hu et al., 2010). We do not have direct measurements of ice crystals, however, and hence investigating the role of the Bergeron-Wegener-Findeisen process would need further experimental effort.

Estimated updraft velocities $V$ and the corresponding maximum $s_{\max }$ are displayed in Table 3 and in Fig. 8. Average values of values of $V$ varied in the range of 0.20 $0.60 \mathrm{~m} \mathrm{~s}^{-1}$ between the cloud events while average value of $s_{\max }$ varied between 0.27 and $0.63 \%$. In comparison, the estimated values for $s_{\max }$ were generally lower, being in the range of 0.18 to $0.26 \%$, for the cloud cases observed during the previous campaign, PaCE-2 (Anttila et al., 2009) but are comparable to the results from the first PaCE campaign where $s_{\max }$ was estimated to vary in the range of 0.2 and $0.5 \%$ (Lihavainen et a., 2008). The values for $s_{\max }$ were consistently higher than $0.4 \%$ for the cases B, C and D. Such high supersaturations are typically observed for cumulus clouds and in marine stratus clouds formed in clean air masses (Seinfeld and Pandis, 1998; Hudson et al., 2010). The lowest values of $s_{\max }$ were estimated for the case A where $s_{\max }$ varied between 0.22 and $0.29 \%$, and such range is comparable to the values estimated in our previous campaign study (see above). To conclude, large differences in the estimated $s_{\max }$ and $\mathrm{V}$ values between the cloud events suggest that there was large variability in meteorological conditions behind the formation of the observed clouds. This also implies that $\mathrm{CCN}$ concentrations at a fixed supersaturation do not provide an accurate proxy for $\mathrm{CDNC}$ when considering the whole data set. Unfortunately there were no $\mathrm{CCN}$ measurements during the cloud events $\mathrm{A}$ and $\mathrm{E}$ so this notion cannot be fully tested against experiments.

From Fig. 8 it can also be seen that the values of $s_{\max }$ are closely linked to those of $V$. A further comparison showed that $s_{\max }$ and $V$ are positively correlated, the degree of correlation being 0.79 (not illustrated here). A physical explanation for this is that higher updraft velocities lead to higher levels of water vapour supersaturation through increased rate of cooling of the air parcel. On the other hand, $s_{\max }$ is expected to depend on the number of $\mathrm{CCN}$ active particles as they act as a sink of water vapour during the cloud formation. To see if we can detect such suppression effect, we compared the values of $s_{\max }$ and $\mathrm{CCN}(0.4 \%)$. The comparison showed that $s_{\max }$ is negatively correlated with $\mathrm{CCN}(0.4 \%)$ with the degree of correlation being 0.63 (not shown). Hence the modeling results suggest that the maximum supersaturations reached in the observed clouds are influenced both by meteorological conditions and, to some extent, the number of $\mathrm{CCN}$ active particles. It is worth noting that $\mathrm{CCN}(0.4 \%)$ was not correlated with observational $D_{50}$ (Sect. 4.3) when calculated CCN concentrations were included into the comparison to fill the gaps in the measurements. To compliment this result, we made similar comparison for the model based values of $D_{50}$. As expected, $D_{50}$ was positively correlated with $\mathrm{CCN}(0.4 \%)$ even though the degree of correlation was rather low, being 0.41 (not shown). Consequently, $D_{50}$ is not as sensitive to the total number of CCN active particles as $s_{\max }$ even though $D_{50}$ is also related to the activation efficiency of a particle population.

The number of cloud droplets inferred from measurements, CDNC, was observed to be strongly correlated with the number of available $\mathrm{CCN}(\mathrm{Sect}$. 4.3). In order to estimate the impact of meteorological conditions to the number of cloud droplets formed, we compared CDNC with the corresponding updraft values (Fig. 9). These two quantities correlate very poorly, the degree of correlation being below $10^{-3}$, which suggests together with the previously presented results that the number of available $\mathrm{CCN}$ was the main factor in determining CDNC during the analyzed cloud cases. This result is consistent with the results from experimental studies of Gillani et al. (1995) and Snider and Brenguier (2000) who concluded that cloud droplet concentrations depend weakly on the updraft velocity for clouds formed in clean air masses (which is the case here). We also did remove the outliers, i.e. those cases where CDNC was outside the range of 50$150 \mathrm{~cm}^{-3}$, from the data displayed in Fig. 9 to see if the lack of correlation might be caused by them, but the degree of correlation between CDNC and V increased consequently only 


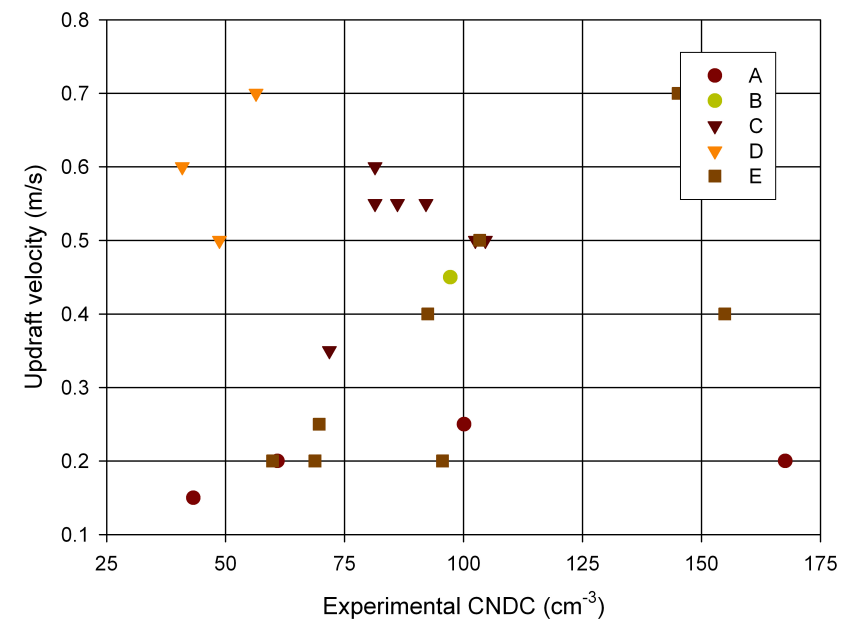

Fig. 9. Cloud droplet number concentrations versus the model based estimates for the updraft velocity.

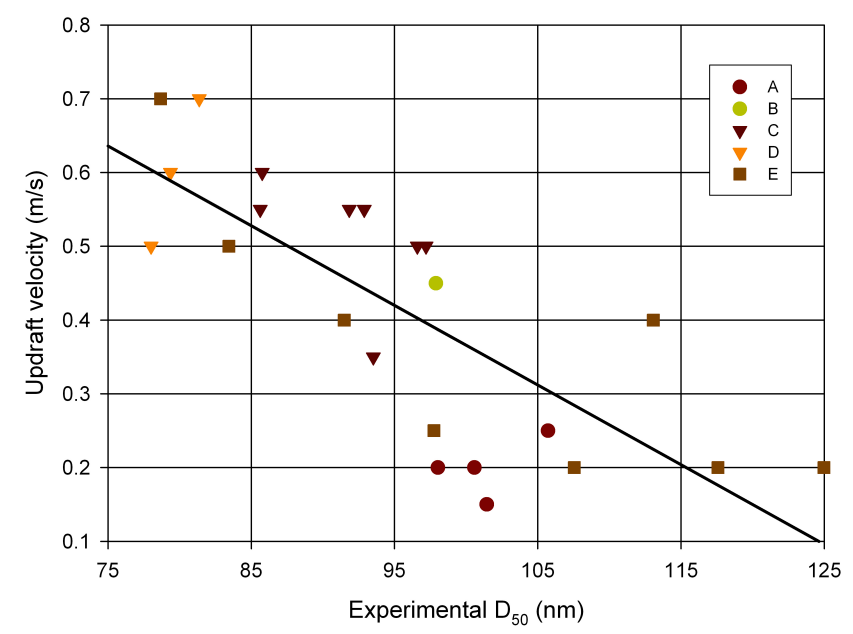

Fig. 10. The diameter corresponding to $50 \%$ activation efficiency $\left(D_{50}\right)$ versus the updraft velocity. The optimal linear fit to the data is also displayed.

to around 0.2. On the other hand, experimental values of $\mathrm{D}_{50}$ correlate with the updraft velocity to some extent, the degree of correlation $\left(R^{2}\right)$ being 0.64 (Fig. 10). A plausible interpretation for this correlation is that large updraft velocities led to large values of $s_{\max }$ which allowed for smaller particles to activate into cloud droplets. Hence the updraft velocity did impact the overall activation efficiency of particles (as quantified by $D_{50}$ ) to some degree while the number of cloud droplets formed was mainly determined by the $\mathrm{CCN}$ spectrum.

It is also of interest to compare the modeled values of CDNC together with $V$ and $s_{\max }$ (Table 3) with the number of CCN at supersaturation $0.4 \%$ (Table 2). The comparison shows that the values of $\mathrm{CCN}(0.4 \%)$ are higher than the corresponding values of $\mathrm{CDNC}$ for the cloud events $\mathrm{B}$ and $\mathrm{C}$ despite the fact that the values of $s_{\max }$ were above $0.4 \%$ in these cases. For the case D, the average values of CDNC and $s_{\max }$ were $49 \mathrm{~cm}^{-3}$ and $0.63 \%$, respectively, while the average value of $\mathrm{CCN}(0.6 \%)$ was $63 \mathrm{~cm}^{-3}$. This comparison shows that the measured $\mathrm{CCN}$ activity of particles is higher than the modeled activation efficiency even when accounting for the experimental uncertainties which were estimated to be 17 and $15 \%$ at supersaturations of 0.4 and $0.6 \%$, respectively (Sect. 5). It should be noted though that comparing $\mathrm{CCN}$ concentrations measured at $25^{\circ} \mathrm{C}$ and $\mathrm{CDNC}$ calculated at the ambient temperature is problematic because the particle $\mathrm{CCN}$ activity depends on the temperature through the Kelvin term. In order to make a consistent comparison, we recalculated the $\mathrm{CCN}$ concentrations at the cloud base temperature which was assumed to be the same as that measured at the station (Table 2). On average, the $\mathrm{CCN}$ concentrations decreased by $13,8,9,10$ and $9 \%$ at the supersaturations 0.2 , $0.4,0.6,0.8$ and $1.0 \%$, respectively. Assuming that the CCN activity of the measured particles displays similar temperature dependence, such decrease together with experimental uncertainties would account for most of the differences between measured $\mathrm{CCN}$ concentrations and calculated CDNC at similar supersaturations. As a further reason, the discrepancies could be caused partly by kinetic limitations in the cloud droplet formation (Nenes et al., 2001). However, for the cloud air masses observed during this study, the resulting differences in the number of cloud droplets and $\mathrm{CCN}$ concentrations at $s_{\max }$ are expected to remain below $10 \%$ (Nenes et al., 2001) which is not sufficient to explain the discrepancy. More likely reason is that the CCN activity of particles is underestimated by the Koehler theory which the cloud model uses to calculate the equilibrium vapor pressure of water above the droplet surface. This notion is supported by the CCN closure study presented in previous section (Fig. 5). In order to evaluate the extent to which this discrepancy affects the estimated values of $s_{\max }$ and $V$, we repeated the calculations while increasing the particles hygroscopic growth factors by $5 \%$. The degree of increase in hygroscopicity was chosen by minimizing the difference between the predicted and measured $\mathrm{CCN}$ concentrations at supersaturation of $0.4 \%$. This approach gives a less accurate description of the particle hygroscopic growth at subsaturated RH in favor of a more accurate description at supersaturated $\mathrm{RH}$ (which is more important for the cloud simulations). On average, the values of $V$ and $s_{\max }$ decreased by 27 and $14 \%$, respectively, compared to the base case results and the corresponding standard deviations were 5 and $3 \%$, respectively. Hence, a small fractional change in the particle hygroscopicity led to notable changes in the estimated values of $V$ and $s_{\max }$. This is due to the Koehler theory according to which small changes in the particle hygroscopicity leads to large changes in the particle critical supersaturation when the particle soluble fraction is small (Bilde and Svennignsson, 2004). The main impact of changing the hygroscopicity was to scale down the estimated values of $V$ and $s_{\max }$, however, and the conclusions presented 
Table 4. The absolute values of the fractional changes in the modeled cloud droplet concentrations, $\Delta \mathrm{CDNC}$, in the three sensitivity cases described in Sect. 6.2. The values are given in percents. Also, the average values are given for each cloud event, and the last column indicates the values of $\triangle \mathrm{CDNC}$ averaged over the whole data set.

\begin{tabular}{lcccccc}
\hline & \multicolumn{4}{c}{$\begin{array}{c}\text { Average } \\
\text { for cloud event }\end{array}$} & & Average \\
\cline { 2 - 6 } Case & A & B & C & D & E & \\
\hline Constant size distribution & 33 & 25 & 13 & 102 & 26 & 34 \\
Constant hygroscopicity & 5 & 29 & 14 & 13 & 14 & 13 \\
Constant updraft velocity & 30 & 0 & 8 & 11 & 16 & 15 \\
\hline
\end{tabular}

above are robust with respect to the estimated degree of uncertainty in the $\mathrm{CCN}$ activity of the particles.

\subsection{Sensitivity studies}

The results described in Sect. 6.1 suggest that the number of cloud droplets formed, CDNC, was closely tied to the particle CCN spectrum whereas meteorology played a secondary role. The $\mathrm{CCN}$ spectrum is determined in turn by the particle size distribution and chemical composition (Andreae and Rosenfeld, 2008). In order to further elucidate the relative importance of these factors to the observed variability of CDNC, we repeated the calculations presented in the last section by keeping one of the following model inputs constant: the particle size distribution, the particle hygroscopicity or the updraft velocity. The values of the other input parameters were the same as in the corresponding base case simulations. The resulting values of CDNC were then compared to the corresponding base case results to assess the relative importance of the considered factors. In the first sensitivity study (termed as "constant size distribution"), the simulations were repeated by using the time-averaged size distribution as an input. Here the averaging was done over all the cloudy time periods considered. In the second study (termed as "constant hygroscopicity"), we calculated first time-averaged distribution of hygroscopic growth factors and then performed the fitting process described in Sect. 3.1 to find the corresponding values of the hygroscopic parameters. The averaging was done over the considered cloudy periods, and the simulations were repeated by using the obtained hygroscopic properties as input. Finally, in the third case (termed as "constant updraft velocity"), we calculated the time-averaged value of the updraft velocity $V$, which was around $0.39 \mathrm{~m} \mathrm{~s}^{-1}$, and then repeated the simulations using the average updraft velocity as input while the other inputs were the same as in the base case calculations.

The absolute values of the fractional changes in CDNC relative to the respective base case simulations, $\triangle \mathrm{CDNC}$, are presented in Table 4 for each set of sensitivity calculations. As seen, the largest changes in CDNC took place on average when the aerosol size distribution was kept constant while the hygroscopicity and updraft velocity were much less impor- tant factors. For the cloud events B and C, however, the modeled values of CDNC showed largest sensitivity to the particle hygroscopicity while the size distribution was the most important factor for the events A, D and E. Regarding the events $\mathrm{B}$ and $\mathrm{C}$, Table 1 shows that $\mathrm{CN}(>100 \mathrm{~nm})$ did not deviate much from the overall average value of $\mathrm{CN}(>100 \mathrm{~nm})$, which was $103 \mathrm{~cm}^{-3}$. On the other hand, the particle hygroscopic growth factors for $100 \mathrm{~nm}$ particles were lower compared to overall average value, which was 1.21 , during the events B and C. These two factors largely account for this particular result. Taken together, the results strengthen our conclusion that the particle size distribution was the dominating factor in the variation of observed CDNC.

It was noted in the previous section that the modeled CCN activity of particles is smaller than the $\mathrm{CCN}$ measurements done at $0.4 \%$ supersaturation suggest. Moreover, this discrepancy could be minimized by increasing the hygroscopic growth factors by $5 \%$. To investigate if these uncertainties in the modeled CCN activity could impact the conclusions drawn from the sensitivity studies we repeated the sensitivity studies while increasing the particle hygroscopicity accordingly. To summarize, the average values of $\triangle \mathrm{CDNC}$ were 33, 8 and $15 \%$ in the cases "constant size distribution", "constant hygroscopicity" and "constant updraft velocity", respectively. The importance of the particle hygroscopicity was thus somewhat decreased compared to the base case simulations, as can be seen from the last column of Table 4 , but the overall differences were small.

\section{Summary and conclusions}

Concurrent measurement of aerosols, cloud condensation nuclei $(\mathrm{CCN})$ concentrations and cloud droplet activation were carried out as a part of the third Pallas Cloud Experiment (PaCE-3) which took place at a ground based site located on northern Finland during the autumn of 2009. Here we have focused on selected cloudy periods to investigate relationships between the aerosol properties, $\mathrm{CCN}$ and size resolved cloud droplet activation.

The estimated number concentration of cloud droplets (CDNC) varied typically between 50 and $150 \mathrm{~cm}^{-3}$ and 
displayed correlation both with the number of particles having sizes over $100 \mathrm{~nm}, \mathrm{CN}(>100 \mathrm{~nm})$, and with the $\mathrm{CCN}$ concentrations at $0.4 \%$ supersaturation, $\mathrm{CCN}(0.4 \%)$. On the other hand, the activated fraction of particles varied strongly between the cloud events, implying that CDNC cannot be estimated on the basis of the total particle number concentrations. Furthermore, the diameter corresponding to the $50 \%$ activated fraction, $D_{50}$, was generally in the range of 80 to $120 \mathrm{~nm}$.

The measured CCN concentrations were compared with the predictions based on an application of the Koehler theory where the measured size distribution and size resolved hygroscopicity were used as input. Assuming that the droplet surface tension is equal to that of water, the measured and predicted CCN concentrations were generally within $30 \%$. It was also noted that the model tends to underpredict the observed CCN activity at supersaturations $0.4 \%$ and above. The second part of the modeling work consisted of simulating size dependent cloud droplet activation with a previously developed air parcel model. By forcing the model to reproduce the experimental values of CDNC, adiabatic estimates for the updraft velocity, $V$, and for the maximum supersaturation reached in the clouds, $s_{\max }$, were derived. Despite some biases, the calculated and measured size resolved activated fractions generally matched each other within experimental uncertainties. The experimental and modeling results together suggest that CDNC was mainly determined by the CCN spectrum (i.e. the particle size and chemical composition) rather than the meteorological conditions as characterized by $V$. However, the estimated updraft velocities displayed a negative correlation with $\mathrm{D}_{50}$ which indicates that meteorology did have an impact on the overall particle activation efficiency. Performed sensitivity studies showed further that the observed variability in CDNC was driven mainly by changes in the particle size distribution while the variations in the updraft velocity and hygroscopicity contributed to a lesser extent.

Following loosely the classification presented by Reutter et al. (2009), the results suggest that the observed clouds were formed on the "aerosol-limited regime" where the number of CCN active particles largely determines CDNC. This is consistent with previous studies on the microphysics of clouds formed in clean air masses (e.g. Twohy et al., 2005). It should be noted, however, that the current study is based on a rather short intensive campaign where the range of atmospheric conditions encountered was limited. Therefore long term simultaneous measurements of aerosols, $\mathrm{CCN}$ and cloud droplet activation are desirable to investigate how the results obtained here compare to larger data sets containing results from different seasons and air mass types. Towards this, our plan is to conduct continuous measurements of the particle physical and chemical properties and connect them with CCN and cloud droplet activation observations at the Pallas field station.
Acknowledgements. The work has been supported financially by the EC projects ACCENT (European Network of Excellence in Atmospheric Composition Change) and EUSAAR (European Supersites for Atmospheric Aerosol Research) as well as by the Academy of Finland Center of Excellence program (project number 1118615). Antti Jaatinen was supported by Kone foundation. Martin Gysel from the Paul Scherrer Institute is acknowledged for providing the data-inversion toolkit for the HTDMA data.

Edited by: A. Petzold

\section{References}

Andreae, M. O. and Rosenfeld, D.: Aerosol-cloud-precipitation interactions. Part 1. The nature and sources of cloud-active aerosols, Earth Sci. Rev., 89, 13-41, 2008.

Anttila, T., Vaattovaara, P., Komppula, M., Hyvärinen, A.-P., Lihavainen, H., Kerminen, V.-M. and Laaksonen, A.: Sizedependent activation of aerosols into cloud droplets at a subarctic background site during the second Pallas Cloud Experiment (2nd $\mathrm{PaCE})$ : method development and data evaluation, Atmos. Chem. Phys., 9, 4841-4854, doi:10.5194/acp-9-4841-2009, 2009.

Anttila, T.: Sensitivity of cloud droplet formation to the numerical treatment of the particle mixing state, J. Geophys. Res., 115, D21205, doi:10.1029/2010JD013995, 2010.

Barahona, D., and Nenes, A.: Parameterization of cloud droplet formation in large-scale models: Including effects of entrainment,J. Geophys. Res., 112, D16206, doi:10.1029/2007JD008473, 2007.

Bilde, M. and Svenningsson, B.: CCN activation of slightly soluble organics: the importance of small amounts of inorganic salt and particle phase, Tellus B, 56, 128-134, 2004.

Conant, W. C., VanReken, T. M., Rissman, T. A., Varutbangkul, V., Jonsson, H. H., Nenes, A., Jimenez, J. L., Delia, A. E., Bahreini, R., Roberts, G. C., Flagan, R. C., and Seinfeld, J. H.: Aerosolcloud drop concentration closure in warm cumulus, J. Geophys. Res., 109, D13204, doi:10.1029/2003JD004324, 2004.

DeCarlo, P. F., Kimmel, J. R., Trimborn, A., Northway, M. J., Jayne, J. T., Aiken, A. C., Gonin, M., Fuhrer, K., Horvath, T., Docherty, K., Worsnop, D. R. and Jimenez, J. L.: Field-Deployable, HighResolution, Time-of-Flight Aerosol Mass Spectrometer, Anal. Chem., 78, 8281-8289, 2006.

Draxler, R. R. and Rolph, G. D.: HYSPLIT (HYbrid Single-Particle Lagrangian Integrated Trajectory) Model access via NOAA ARL READY Website (http://ready.arl.noaa.gov/HYSPLIT. php), NOAA Air Resources Laboratory, Silver Spring, MD, USA, 2012.

Duplissy, J., Gysel, M., Sjogren, S., Meyer, N., Good, N., Kammermann, L., Michaud, V., Weigel, R., Martins dos Santos, S., Gruening, C., Villani, P., Laj, P., Sellegri, K., Metzger, A., McFiggans, G. B., Wehrle, G., Richter, R., Dommen, J., Ristovski, Z., Baltensperger, U., and Weingartner, E.: Intercomparison study of six HTDMAs: results and recommendations, Atmos. Meas. Tech., 2, 363-378, doi:10.5194/amt-2-363-2009, 2009.

Dusek, U., Frank, G. P., Hildebrandt, L., Curtius, J., Schneider, J., Walter, S., Chand, D., Drewnick, F., Hings, S., Jung, D., Borrmann, S., and Andreae, M.O.: Size matters more than chemistry for cloud-nucleating ability of aerosol particles, Science, 312, 1375-1378, 2006. 
Forster, P., Ramaswamy, V., Artaxo, P., Berntsen, T., Betts, R., Fahey, D. W., Haywood, J., Lean, J., Lowe, D. C., Myhre, G., Nganga, J., Prinn, R., Raga, G., Schulz, M., and Van Dorland, R.: Changes in Atmospheric Constituents and in Radiative Forcing. In: Climate Change 2007: The Physical Science Basis. Contribution of Working Group I to the Fourth Assessment Report of the Intergovernmental Panel on Climate Change, edited by: Solomon, S., Qin, D., Manning, M., Chen, Z., Marquis, M., Averyt, K. B., Tignor, M., and Miller, H. L., Cambridge University Press, Cambridge, UK and New York, NY, USA, 2007.

Fountoukis, C., Nenes, A., Meskhidze, N., Bahreini, R., Conant, W. C., Jonsson, H., Murphy, S., Sorooshian, A., Varutbangkul, V., Brechtel, F., Flagan, R. C., and Seinfeld, J. H.: Aerosol-cloud drop concentration closure for clouds sampled during the International Consortium for Atmospheric Research on Transport and Transformation 2004 campaign, J. Geophys Res., 112, D10S30, doi:10.1029/2006JD007272, 2007.

Ghan, S. J. and Schwartz, S. E.: Aerosol properties and processes - A path from field and and laboratory measurements to global climate models, B. Am. Meteorol. Soc., 88, 1059-1083, 2007.

Ghan, S. J., Abdul-Razzak, H., Nenes, A., Ming, Y., Liu, X., Ovchinnikov, M., Shipway, B., Meskhidze, N., Xu, J., and Shi, X.: Droplet nucleation: Physically-based parameterizations and comparative evaluation, J. Adv. Model. Earth Syst., 3, M10001, doi:10.1029/2011MS000074, 2011.

Gillani, N. V., Schwartz, S. E., Leaitch, W. R., Strapp, J. W. and Isaac, G. A.: Field observations in continental stratiform clouds: Partitioning of cloud particles between droplets and unactivated interstitial aerosols, J. Geophys. Res., 100, 18687-18706, doi:10.1029/95JD01170, 1995.

Gysel, M., McFiggans, G. B., and Coe, H.: Inversion of tandem differential mobility analyser (TDMA) measurements, J. Aerosol Sci., 40, 134-151, doi:10.1016/j.jaerosci.2008.07.013, 2009.

Hatakka, J., Aalto, T., Aaltonen, V., Aurela, M., Hakola, H., Komppula, M., Laurila, T., Lihavainen, H., Paatero, J., Salminen, K., and Viisanen, Y.: Overview of the atmospheric research activities and results at Pallas GAW station, Boreal Environ. Res., 8, 365-384, 2003.

Henning, S., Weingartner, E., Schmidt, S., Wendisch, M., Gäggeler, H. W., and Baltensperger, U.: Size-dependent aerosol activation at the high-alpine site Jungfraujoch ( $3580 \mathrm{~m}$ asl), Tellus, 54B, 82-95, 2002.

Hu, Y., Rodier, S., Xu, K., Sun, W., Huang, J., Lin, B., Zhai, P., and Josset, D.: Occurrence, liquid water content, and fraction of supercooled water clouds from combined CALIOP/IIR/MODIS measurements, J. Geophys. Res., 115, D00H34, doi:10.1029/2009JD012384, 2010.

Hudson, J. G.: Variability of the relationship between particle size and cloud-nucleating ability, Geophys. Res. Lett., 34, L08801, doi:10.1029/2006GL028850, 2007.

Hudson, J. G., Noble, S., and Jha, V.: Stratus cloud supersaturations, Geophys. Res. Lett., 37, L21813, doi:10.1029/2010GL045197, 2010.

Jaatinen, A., Hyvärinen, A.-P., Romakkaniemi, S., Hao, L., Kortelainen, A., Miettinen, P., Komppula, M., Leskinen, A., Anttila, T., Smith, J. N., and Laaksonen, A.: The 3rd Pallas Cloud Experiment: consistency between the hygroscopic growth and CCN activity parameterisations, in preparation, 2012.
Jurányi, Z., Gysel, M., Weingartner, E., DeCarlo, P. F., Kammermann, L., and Baltensperger, U.: Measured and modelled cloud condensation nuclei number concentration at the high alpine site Jungfraujoch, Atmos. Chem. Phys., 10, 7891-7906, doi:10.5194/acp-10-7891-2010, 2010.

Kammermann, L., Gysel, M., Weingartner, W., Herich, H., Cziczo, D.J., Holst, T., Svenningsson, B., Arneth, A., and Baltensperger, U.: Subarctic atmospheric aerosol composition: 3. Measured and modeled properties of cloud condensation nuclei, J. Geophys. Res., 115, D04202, doi:10.1029/2009JD012447, 2010.

Kivekäs, N., Kerminen, V.-M., Raatikainen, T., Vaattovaara, P., and Lihavainen, H.: Physical and chemical characteristics of the activating particles during the Second Pallas Cloud Experiment (Second PaCE), Boreal. Environ. Res., 14, 515-526, 2009.

Kleinman, L. I., Daum, P. H., Lee, Y.-N., Lewis, E. R., Sedlacek III, A. J., Senum, G. I., Springston, S. R., Wang, J., Hubbe, J., Jayne, J., Min, Q., Yum, S. S., and Allen, G.: Aerosol concentration and size distribution measured below, in, and above cloud from the DOE G-1 during VOCALS-REx, Atmos. Chem. Phys., 12, 207223, doi:10.5194/acp-12-207-2012, 2012.

Komppula, M., Lihavainen, H., Kerminen, V.-M., Kulmala, M., and Viisanen, Y.: Measurements of cloud droplet activation of aerosol particles at a clean subarctic background site, J. Geophys. Res., 110, D06204, doi:10.1029/2004JD005200, 2005.

Laaksonen, A., Vesala, T., Kulmala, M., Winkler, P. M., and Wagner, P. E.: Commentary on cloud modelling and the mass accommodation coefficient of water, Atmos. Chem. Phys., 5, 461-464, doi:10.5194/acp-5-461-2005, 2005

Levin, E. J. T., Prenni, A. J., Petters, M. D., Kreidenweis, S. M., Sullivan, R. C., Atwood, S. A., Ortega, J., DeMott, P. J., and Smith, J. N.: An annual cycle of size-resolved aerosol hygroscopicity at a forested site in Colorado, J. Geophys. Res., 117, D06201, doi:10.1029/2011JD016854, 2012.

Lihavainen, H., Kerminen, V.-M., Komppula, M., Hyvärinen, A.P., Laakia, J., Saarikoski, S., Makkonen, U., Kivekäs, N., Hillamo, R., Kulmala, M., and Viisanen, Y.: Measurements of the relation between aerosol properties and microphysics and chemistry of low level liquid water clouds in Northern Finland, Atmos. Chem. Phys., 8, 6925-6938, doi:10.5194/acp-8-6925-2008, 2008.

McFiggans, G., Artaxo, P., Baltensperger, U., Coe, H., Facchini, M. C., Feingold, G., Fuzzi, S., Gysel, M., Laaksonen, A., Lohmann, U., Mentel, T. F., Murphy, D. M., O’Dowd, C. D., Snider, J. R., and Weingartner, E.: The effect of physical and chemical aerosol properties on warm cloud droplet activation, Atmos. Chem. Phys., 6, 2593-2649, doi:10.5194/acp-6-2593-2006, 2006.

Mertes, S., Lehmann, K., Nowak, A., Massling, A., and Wiedensohler, A... Link between aerosol hygroscopic growth and droplet activation observed for hill-capped clouds at connected flow conditions during FEBUKO, Atmos. Environ., 39, 4247-4256, 2005.

Meskhidze, N., Nenes, A., Conant, W. C., and Seinfeld, J. H.: Evaluation of a new cloud droplet activation parameterization with in situ data from CRYSTAL-FACE and CSTRIPE, J. Geophys. Res., 110, D16202, doi:10.1029/2004JD005703, 2005.

Morales, R., Nenes, A., Jonsson, H., Flagan, R. C., and Seinfeld, J. H.: Evaluation of an entraining droplet activation parameterization using in situ cloud data,J. Geophys. Res., 116, D15205, doi:10.1029/2010JD015324, 2011. 
Nenes, A., Ghan, S., Abdul-Razzak, H., Chuang, P., and Seinfeld, J. H.: Kinetic limitations on cloud droplet formation and impact on cloud albedo, Tellus, Ser. B, 53, 133-149, 2001.

Noone, K. J., Ogren, J. A., Hallberg, A., Heintzenberg, J., Ström, J., Hansson, H.-C., Svenningsson, I. B., Wiedensohler, A., Fuzzi, S., Facchini, M. C., Arends, B. G., and Berner, A.: Changes in aerosol size- and phase distributions due to physical and chemical processes in fog, Tellus B 44, 489-504, 1992.

Penner, J. E., Quaas, J., Storelvmo, T., Takemura, T., Boucher, O., Guo, H., Kirkevåg, A., Kristjánsson, J. E., and Seland, Ø.: Model intercomparison of indirect aerosol effects. Atmos. Chem. Phys., 6, 3391-3405, doi:10.5194/acp-6-3391-2006, 2006.

Petters, M. D. and Kreidenweis, S. M.: A single parameter representation of hygroscopic growth and cloud condensation nucleus activity, Atmos. Chem. Phys., 7, 1961-1971, doi:10.5194/acp-71961-2007, 2007.

Quinn, P. K., Bates, T. S., Coffman, D. J., and Covert, D. S.: In?uence of particle size and chemistry on the cloud nucleating properties of aerosols, Atmos. Chem. Phys., 8, 1029-1042, doi:10.5194/acp-8-1029-2008, 2008.

Reutter, P., Su, H., Trentmann, J., Simmel, M., Rose, D., Gunthe, S. S., Wernli, H., Andreae, M. O., and Pöschl, U.: Aerosol- and updraft-limited regimes of cloud droplet formation: influence of particle number, size and hygroscopicity on the activation of cloud condensation nuclei (CCN), Atmos. Chem. Phys., 9, 70677080, doi:10.5194/acp-9-7067-2009, 2009.

Roberts, G. C. and Nenes, A.: A continuous-flow streamwise thermal gradient $\mathrm{CCN}$ chamber for atmospheric measurements, Aerosol Sci. Tech., 39, 206-221, 2005.

Rogers, R. R. and Yau, M. K., A Short Course in Cloud Physics, Pergamon, Tarrytown, NY, USA, 393 pp., 1989.

Romakkaniemi, S., McFiggans, G., Bower, K. N., Brown, P., Coe, H., and Choularton, T. W.: A comparison between trajectory ensemble and adiabatic parcel modeled cloud properties and evaluation against airborne measurements, J. Geophys. Res., 114, D06214, doi:10.1029/2008JD011286, 2009.

Ruehl, C. R., Chuang, P. Y., and Nenes, A.: Aerosol hygroscopicity at high (99 to $100 \%)$ relative humidities, Atmos. Chem. Phys., 10, 1329-1344, doi:10.5194/acp-10-1329-2010, 2010.

Snider, J. R. and Brenguier, J. L.: Cloud condensation nuclei and cloud droplet measurements during ACE-2, Tellus B, 52, 828848, 2000.

Snider, J. R., Guibert, S., Brenguier, J.-L., and Putaud, J.-P.: Aerosol activation in marine stratocumulus clouds: 2. Köhler and parcel theory closure studies, J. Geophys. Res., 108, 8629, doi:10.1029/2002JD002692, 2003.
Svenningsson, B., Hansson, H.-C., Wiedensohler, A., Noone, K. J., Ogren, J. A., Hallberg, A., and Colvile, R.: Hygroscopic growth of aerosol particles and its influence on nucleation scavenging in cloud: experimental results from Kleiner Feldberg, J. Atmos. Chem., 19,129-151, 1994.

Svenningsson, B., Hansson, H.-C., Martinsson, B., Wiedensohler, A., Swietlicki, E., Cederfelt, S.-I., Wendisch, M., Bower, K. N., Choularton, T. W., and Colvile, R. N.: Cloud droplet nucleation scavenging in relation to the size and hygroscopic behaviour of aerosol particles, Atmos. Environ., 31, 2463-2475, 1997.

Twohy, C. H., Petters, M. D., Snider, J. R., Stevens, B., Tahnk, W., Wetzel, M., Russell, L., and Burnet, F.: Evaluation of the aerosol indirect effect in marine stratocumulus clouds: Droplet number, size, liquid water path, and radiative impact, J. Geophys. Res., 110, D08203, doi:10.1029/2004JD005116, 2005.

Verheggen, B., Cozic, J., Weingartner, E., Bower, K., Mertes, S., Connolly, P., Gallagher, M., Flynn, M., Choularton, T., and Baltensperger, U.: Aerosol partitioning between the interstitial and condensed phase in mixed-phase clouds, J. Geophys. Res., 112, D23202, doi:10.1029/2007JD008714, 2007.

Wex, H., Stratmann, F., Hennig, T., Hartmann, S., Niedermeier, D., Nilsson, E., Ocskay, R., Rose, D., Salma, I., and Ziese, M.: Connecting hygroscopic growth at high humidities to cloud activation for different particle types, Environ. Res. Lett., 3, 035004, doi:10.1088/1748-9326/3/3/035004, 2008.

Wiedensohler, A., Birmili, W., Nowak, A., Sonntag, A., Weinhold, K., Merkel, M., Wehner, B., Tuch, T., Pfeifer, S., Fiebig, M., Fjäraa, A. M., Asmi, E., Sellegri, K., Depuy, R., Venzac, H., Villani, P., Laj, P., Aalto, P., Ogren, J. A., Swietlicki, E., Williams, P., Roldin, P., Quincey, P., Hüglin, C., Fierz-Schmidhauser, R., Gysel, M., Weingartner, E., Riccobono, F., Santos, S., Grüning, C., Faloon, K., Beddows, D., Harrison, R., Monahan, C., Jennings, S. G., O’Dowd, C. D., Marinoni, A., Horn, H.-G., Keck, L., Jiang, J., Scheckman, J., McMurry, P. H., Deng, Z., Zhao, C. S., Moerman, M., Henzing, B., de Leeuw, G., Löschau, G., and Bastian, S.: Mobility particle size spectrometers: harmonization of technical standards and data structure to facilitate high quality long-term observations of atmospheric particle number size distributions, Atmos. Meas. Tech., 5, 657-685, doi:10.5194/amt5-657-2012, 2012.

Yum, S. S., Hudson, J. G., and Xie, Y.: Comparisons of cloud microphysics with cloud condensation nuclei spectra over the summertime Southern Ocean, J. Geophys. Res., 103, 16625-16636, doi:10.1029/98JD01513, 1998. 